QUALITY MANAGEMENT AND FOOTWEAR VALUE CHAIN. A CASE STUDY OF FIBALCO

\author{
ALEXANDRA LUCA, ALINA IOVAN DRAGOMIR \\ "Gheorghe Asachi" Technical University of Iasi, Faculty of Industrial Design and Business \\ Management, 28 D. Mangeron, Iasi, Romania, alexandra.luca@tuiasi.ro; \\ adragomir@tex.tuiasi.ro
}

\begin{abstract}
In the complicated economic context, will survive only companies who can obtain recognizable products, with higher quality and who are economically efficient by reducing losses of any kind. An example of good practices is represented by SC Fibalco SRL, a footwear company from Craiova, Romania, which emphasizes the development strategy of the Quality Management and the value chain analysis. Fibalco's success is explained by the fact that the value chain analysis is a component of the quality management and the responsibility is distributed pyramidally starting from each employee to the top management. One of the chains in Fibalco's value chain is Industrialization of the new product, which is an element of originality and makes the difference between the theoretical and the practical approaches from the perspective of launching a new product on the market. Due to the Industrialization of the new product chain, in order to make it efficiently reproducible, many risks of failure are eliminated from the design phase, especially those related to the technical execution of the product. The result is a "clean" footwear product with clear lines without unnecessary sophistication. This paper demonstrates that the implementation of quality management and a complex value chain adapted to the company needs leads to brand value and loyalty among consumers.
\end{abstract}

Keywords: footwear, value chain, quality management.

\title{
INTRODUCTION
}

In the current economic situation, marked by a crisis of overproduction, the Romanian footwear manufacturers are facing big challenges related to the market access of the products on one hand and to their sale on the other.

In this complicated economic context, only those who can obtain recognizable products, with higher quality and who are economically efficient by reducing losses of any kind, will survive.

An example of good practices is represented by SC Fibalco SRL a footwear company from Craiova, Romania, which emphasizes the development strategy of the Quality Management and the value chain analysis. Although these two are most often seen and implemented separately and independently, Fibalco's management has integrated and correlated them in the company's development strategy, in order to increase business performance. The experience of this company shows us that understanding the dynamics of the value chain and the importance of quality, will generate positive effects on business performance.

\section{Quality Management}

After the Second World War, two important forces appeared with an impact on the concept of quality: the Japanese revolution in quality and the awareness of the importance of quality in customer perception. These two forces have led to a change in mentality towards quality.

Over time, the literature has revealed various definitions and approaches to the concept of quality and the quality management. The most well-known definitions of quality, offered by quality gurus are: Dr. W.E. Deming defines quality as "The efficient 
production of the quality that the market expects"; Crosby P.B. (1979) considers that "Quality is conformance to customer requirements"; Feigenbaum A.V. (1961) affirms that "Quality is what the customer says it is"; Dr. Taguchi G. (1986) "Quality is the loss that a product costs to the society after being shipped to the customer". Another definition is offered by Dr. Juran J.: "Quality is the fitness of use" (Bisgaard S., 2008, Juran J., 1967). Prof. Ishikawa K. is considered one of the "parents" of quality and total quality control (TQC). He believes that TQL is responsible for every element of the company that studies, practices and participates in quality control (Kumar P. et al. 2016). According to ISO 9001:2000 (Quality Management Systems, 2000-12) the quality is "degree to which a set of inherent characteristics (distinguishing features) fulfils requirements".

\section{Value Chain}

The concept of value chain appeared in the early '80s as the total of activities necessary to obtain a product. The value chain concept was developed by Porter M.E. in 1985 as a management concept that describes a company as a conglomeration of tasks (activities) divided into main tasks and support tasks.

This approach aims to improve the company's performance, to create added value for the company and the customer and also to reduce costs by eliminating unprofitable activities. Over the years, the value chain has evolved by integrating activities that increase added value and take into account the "buyer's voice".

\section{CASE STUDY}

SC Fibalco SRL is a footwear company, 100\% Romanian, with an experience of over 20 years in the field, specialized in the production of snickers.

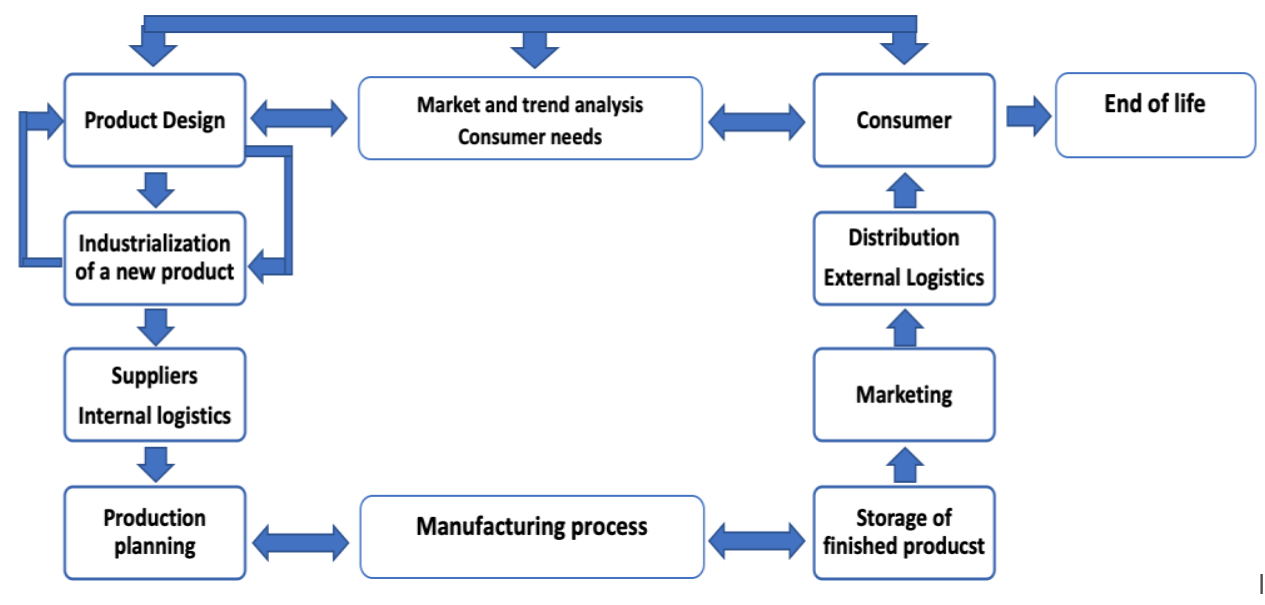

Figure 1. Fibalco's footwear value chain

In their management concept they have developed and included their own value chain adapted to the consumer needs and their technological resources. In the figure 1 is presented Fibalco's footwear value chain.

https://doi.org/10.24264/icams-2020.III.12 
The footwear value chain proposed by Fibalco, is a value chain in a closed loop that focuses on the consumer (it starts with the consumer needs and ends with consumer use of the product)

\section{Market and Trend Analysis and Defining Consumer Needs}

In this stage, the market research is performed by analyzing the offer of direct competitors (those who sell the same products, with the same quality at the same prices) but also of the potential ones (those who produce the same products with better / worse quality at higher or lower prices). In this phase is established the targeted audience from a geographical, demographic and financial point of view and the habits and frequency of purchase for this segment. In order to accomplish this activity, marketing tools such as physical or online surveys, questionnaires, in-store interviews, participation at fairs and exhibitions are used.

A macro-trend is the "wellness" boom - it appears in the context that includes the crisis of the global health systems, the choice to adopt a healthy lifestyle and the rejection of unrealistic esthetic ideals.

To meet the market needs, the company Fibalco with the experience gained in collaboration with brands from Italy and the Netherlands, created its own brand L'Escarpe.

\section{Product Design}

The design of a sneaker is a very complex operation and follows a precise process, it has specific functions and features. This stage includes stylistic proposals, making the model sketch, the pattern model, choosing the last, the soles, the materials and accessories. Another important step is to calculate the price of the product after the sample is made.

\section{Industrialization of a New Product to Make it Efficiently Reproducible}

This link of the value chain elaborated by Fibalco represents an element of originality and makes the difference between the theoretical and the practical thinking from the perspective of launching a new product on the market.

The activities that subscribe to this stage have in view: the elaboration of the technical documentation, the elaboration of the manufacturing process, as well as the establishment of the quality standard of the product whose sample was made in the previous stage. These are compared with the existing equipment in the factory, with the stocks of available materials and with the supply possibilities.

The execution times of some operations are analyzed and proposals / modifications are made in order to streamline the activity and to reduce costs.

\section{Supply Chain and Internal Logistics}

The activity at the level of this link has several main components: the management of the relationship with the suppliers, the management of the inputs of raw materials and materials, the management of the stocks, the management of the waste and the coordination of the internal transport. 


\section{Planning Production}

Planning production is an important stage that covers many activities such as: to respect delivery times, quality and safety at work, ensuring the availability of production equipment, ensuring the synchronization of material and manufacturing flows, ensuring the training and proper development of staff, and also the coordination of the occupational health and safety process.

\section{Manufacturing Process}

The production process is structured on 3 workshops corresponding to the operations of cutting, joining and lasting the product. The 3 workshops have a delimitation without walls to facilitate communication between them. For each operation, a technical file is elaborated, which includes information regarding the setting parameters of the operation and the way of accomplishing them in images and text. The production process ends with the packaging, in the L'Escarpe packaging box.

\section{Storage of Finished Products}

The product boxes are stored in the finished product warehouse, considering the easy access to them.

\section{Marketing and External Logistics}

These two components are especially important in order to ensure the success of the company.
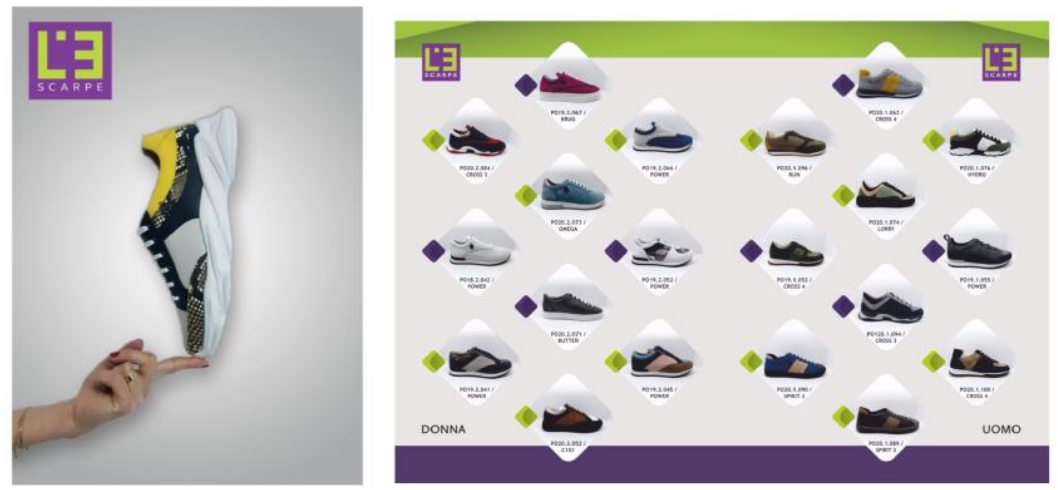

Figure 2. Posters and flyers of Fibalco

The marketing component includes all the actions necessary to transform the ordinary consumer into a consumer promotion vector. To achieve this, promotional activities are carried out through online advertising, the use of social networks, invitations in the network, the creation of posters, flyers and presentation catalogs sent to loyal and targeted customers. In the figure 2 are presented some posters and flyers.

The marketing component also deals with the impact analysis of the promotion actions and of the position of the product on the market. Figure 3 presents the impact analysis of Fibalco's online advertising.

https://doi.org/10.24264/icams-2020.III.12 


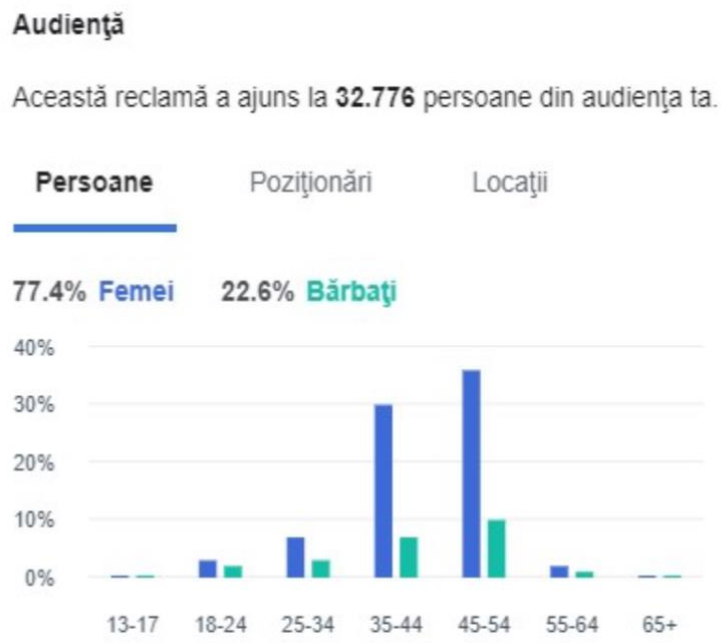

Figure 3. Impact analysis of online advertising

Online advertising was made through social media and the results shows that most of the people interested are women between age of 35 and 54. The analysis shows that over $99 \%$ of potential customers have seen online ads/catalogs using the mobile application. The brand is present in all the historical provinces of the country and highlights the potential growth of the company.

The external logistics component includes finding sales agents to propose products to potential buyers and to promote the brand, but also the delivery and organization of transport to warehouses, stores or consumer.

\section{Final Consumer}

SC Fibalco SRL sells the products in its own stores, both physically and online, but also to other specialized stores. The final consumer is the one who really determines the success or not of a product. The consumer's perception can be influenced by advertising campaigns, testimonials, fashion, sales level but also after-sales services.

A condition of success is the creation of an identity that makes the product recognizable.

\section{End of Life}

This activity is positioned outside the closed loop of the value chain and falls under the responsibility of the final consumer. This situation happened in almost $99 \%$ of footwear manufacturers around the world, except for a few very large companies, which can afford seasonal campaigns such as buy back or collection of used footwear.

Without the involvement of the authorities and programs to support producers in order to be encouraged to receive used footwear, which will then be taken over and processed by specialized companies, the used footwear will continue to reach landfills.

The value chain developed by Fibalco has not explicitly assigned a link for quality control activities. This is explained by the fact that the value chain analysis is a component of the quality management, and the quality control is distributed 
pyramidally and is the responsibility of each employee in each department, of each workshop or service manager.

\section{CONCLUSIONS}

The company's success is based on the fact that they are realistic about the company's development projects, preferring small but safe steps that provide stability and trust to employees and partners. They do not risk in unrealistic projects, being rather traditionalists but permanently open and receptive to the new.

The advantages of implementing the value chain in the company strategy was: an efficient programming of the production, an efficient distribution of the products only in the places where is demand and in the necessary quantities which leads to a stock reduction of finished products.

Due to the Industrialization of the new product chain, in order to make it efficiently reproducible, many risks of failure are eliminated from the design phase, especially those related to the technical execution of the product. The result is a "clean" footwear product with clear lines without unnecessary sophistication.

The implementation of quality management, by assuming the goal of "zero defects" and sharing responsibilities related to quality and quality control to all employees of the company, gives them an advantage over the competitor.

\section{Acknowledgements}

This work has been carried out as part of a Master programme (Product Development of Footwear and Leather Goods) at Faculty of Industrial Design and Business Management, Iasi, Romania. Acknowledgements are also due to Liviu Budică, the manager of SC Fibalco SRL.

\section{REFERENCES}

Bisgaard, S. (2008), “Quality Management and Juran's Legacy”, Quality Engineering, 20(4), 390401, https://doi.org/10.1080/08982110802317398.

Chandrupatla, T.R. (2009), Quality and Reliability in Engineering, Rowan University, New Jersey, ISBN: 978052151522.

Crosby, P. (1979), Quality is free: the art of making quality certain, New York: McGraw-Hill, ISBN 0-07014512-1.

Deming, E.W. (2000), Out of the Crisis, Massachusetts Institute of Technology, by permission of the MIT Press.

Feigenbaum, A.V. (1961), Total Quality Control, New York, McGraw-Hill, OCLC 250573852.

Ishikawa, K. (1968), Guide to Quality Control, Tokyo: Asian Productivity Organization.

ISO 9001:2000, Quality Management Systems, (2000-12), https://www.iso.org/standard/21823.html.

Juran, J. (1967), Management of Quality Control, New York, New York, OCLC 66818686.

Kumar Pradeep, M., Raju, N.V.S. and Satish, K.M.V. (2016), "Quality of quality definition - An analysis", International Journal of Scientific Engineering and Technology, 5(3), https://doi.org/10.17950/ijset/v5s3/304.

Porter, M.E. (1985), Competitive Advantage: Creating and Sustaining Superior Performance, New York: Simon and Schuster, ISBN 9781416595847.

Taguchi, G. (1986), Introduction to Quality Engineering, White Plains, NY: Asian Productivity Organization, UNIPUB.

Taguchi, G. (1988), “The Development of Quality Engineering”, ASI Journal, 1, 1(1-4).

https://doi.org/10.24264/icams-2020.III.12 